\title{
Radical Uncertainty, Dynamic Competition and a Model of the Business Cycle: The Implications of a Measure and an Explanation of What Is Supposed Non-Measurable and Non-Explainable
}

\author{
Angelo Fusari ${ }^{1}$ \\ ${ }^{1}$ Institute of Economic Programming (ISPE), Institute of Studies and Economic Analyses (ISAE), Italy \\ Correspondence: Angelo Fusari, Via Voltaire, 18, 00137 Roma, Italy. Tel: 34-6308-9717. E-mail: \\ anfusari@hotmail.it
}

Received: March 2, 2013 Accepted: April 8, 2013 Online Published: May 14, 2013

doi:10.5539/ijbm.v8n12p8 URL: http://dx.doi.org/10.5539/ijbm.v8n12p8

\begin{abstract}
The influence of radical uncertainty and expectations on economic behaviour is indisputable, whether on entrepreneurship, innovation, investment, or the behaviour that contributes to the business cycle. It is rather surprising, therefore, to see widespread ambiguities in accounts of this crucial aspect of business life and, indeed, human existence. In particular, the frequent assumption ex hypothesis that radical uncertainty is non-measurable and non-explainable constitutes a major misunderstanding that obstructs the analysis of economic growth and development and, more generally, the study of economic dynamics.

This essay first of all underlines the conceptual difference between uncertainty and expectations. It then establishes the possibility and delineates a method of measuring true or radical uncertainty by means of the monthly EU business tendency surveys. This method allows the derivation from these surveys of both more and better information than they at present provide, and also some indicators that are relevant mainly in an evolutionary perspective. In order to obtain a deeper understanding of such procedures, some applications have been carried out. A model of dynamic competition and the business cycle centred on the relation between innovation and uncertainty is then specified and tested using a FIML estimator.
\end{abstract}

Keywords: business tendency surveys, uncertainty, business cycle, innovation, simultaneous estimation

\section{Introduction}

A strange and elusive spectre haunts economists and businessmen - the spectre of uncertainty. Here we refer to so called 'true' or 'radical uncertainty', that is, uncertainty that cannot be represented by probability distributions but is the result of the limits of human knowledge and hence an expression of human ignorance. But such a specification is not always made and, indeed, general and widespread conceptual misconceptions and ambiguities concerning the definition and theoretical status of uncertainty make this phenomenon embarrassing to the theoretical economist. Radical uncertainty may be dampened by the obtaining of information; but is likely to be stimulated by social change and innovation. Thus, the presence and influence of 'radical uncertainty' tends to grow with the increasing innovation driving the dynamism of modern economies. Indeed, one of the main implications of the Schumpeterian teaching on innovation concerns the rise of endogenous uncertainty and its effects on the economy. But such an implication was almost ignored by Schumpeter and continues to be disregarded by many of his followers. This paper attempts to remedy this situation.

Students of the firm and the schools of business administration and organization are paying growing attention to the phenomenon of uncertainty. But widespread conceptual ambiguities persist, in particular the identification of uncertainty with known probability distributions that, as such, expresses probabilistic certainty (Arrow 1953 and 1984, Savage 1954, De Finetti 1964, Harsanyi 1967, Kahneman and Tversky 1979, Machina 1982, Pindyck 1991, Lupton 2003). On the other side, many students who emphasize the distinction between risk and uncertainty (Knight 1921, Keynes 1937, Hayek 1937, Kirzner 1973 and 1985, Lawson 1985, Shackle 1990) have unanimously drawn, from the fact that uncertainty cannot be represented by definition through known distributions of probability, the conclusion that it cannot be measured at all. It is true that heterodox economists (Nelson and Winter 1982, Davidson 1988 and 1994, Dow 1995, Simon 1997, Cantner, Hanusch and Pyka 1998, Hodgson 1999, Morroni 2006, Scazzieri et. al. 2011) do emphasize the limits of knowledge, radical uncertainty 
and the associated notion of bounded rationality; but, for the most part, they persist in considering uncertainty as a sort of vague atmosphere permeating reality, which it is impossible to overlook, but also impossible to measure and hence obliging to plausible reasoning.

The resulting absence of data on and quantitative indicators of radical uncertainty represent a serious and embarrassing lacuna that entails, among other things, that students who place importance on quantitative analysis are obliged to use specifications with probability distributions as a means of quantitatively expressing uncertainty. This paper will attempt to remedy this situation.

The plan of this essay is as follows. Section 2 points out the difference between expectation and uncertainty. Section 3 explores the volatility of opinion, highlights the inability of the Business Tendency Surveys (BTS) data as usually computed to represent the intensity of the relationship between registered changes of opinions and actual results, and delineates some ways of calculating the degree of radical uncertainty from these surveys and some other indicator useful for the interpretation of surveys data. Section 4 presents some applications concerning the relationship between uncertainty and the size of the firm. In addition, this section discusses the relationship between uncertainty and the 'business confidence indicator' and carries out some econometric estimates on this matter; moreover, the section presents some other applications and corrections concerning BTS data, mainly based on the degree of permanence of the registered opinions. Section 5 extends the question of uncertainty to a wider theoretical perspective centred on the notion of dynamic competition; it presents a model with innovation and uncertainty and its extension to the business cycle and brings to the topic an econometric test that uses a FIML estimator (Note 1).

\section{Clarification of Notions: Uncertainty versus Expectations}

Radical uncertainty refers to uncertain events that lack an objective or subjective probability distribution. It may seem at first sight that the notion of subjective probability, that is, the degree of personal confidence that an event may happen, and the connected notion of expectation, express a measure of uncertainty. But this is mistaken. It is therefore important to underline that expectation does not represent implied uncertainty, but just an opinion. While personal degree of confidence and expectation are subjective entities expressing anticipation and hope, our research is concerned with ascertaining an objective measure of uncertainty, where uncertainty results from the limits of knowledge and is thus an expression of the degree of 'ignorance'; such a measure is not given by people's expectations but rather by the instability and/or delusory nature of their expectations (Note 2).

Expectation, then, is, in a certain sense, a pretension of knowledge, while uncertainty is an expression of cognitive impotence. Again, uncertainty expresses a disability caused by the limited reach of knowledge, while, and by contrast, expectation is the expression of an attempt to penetrate the fog of cognitive vagueness, that is, a reaction against uncertainty. Because they are different phenomena, the effects of uncertainty on economic variables differ from those due to expectations. The distinction between expectations and uncertainty is illustrated by our identification of changes in or the volatility of firms' opinions as an indicator of uncertainty. In fact, this indicator merely expresses the fragility of expectations.

Another point deserves attention. It is possible to estimate the value of some proxies that provide a measure of expectations. But the accuracy of the estimation of such expectations is questionable. Economists claim to have formulated analytical expressions of static expectations, adaptive expectations, and rational expectations. These expressions offer some arbitrary and often overly simplified formalisations; substantially, they share the assumption of perfect knowledge. But each entrepreneur has his own proper expectations, the degree of accuracy of which will only appear ex post. It does not make sense to suppose some general rule of formation of expectations, especially not in the case of entrepreneurship which is, in its very nature, action in the face of radical uncertainty (Note 3).

But the key point is that, while both uncertainty and expectations are measurable, uncertainty is a different thing altogether from expectation. The importance of an objective measure of uncertainty is indisputable. For instance, 'decision theory' can be substantially improved if a measure of true (or radical) uncertainty is conjoined to a subjective distribution of probability. Such a measure is also indispensable for the analysis of dynamic competition and the connected business cycle, as we shall see in Section 5. Nevertheless, it appears an exaggerated pretension to offer a general solution to the problem of measuring uncertainty. To grasp the spirit of this elusive variable more than one quantitative indicator must be defined, as we shall see in the next section; and some indicator resulting from a weighted average of various indicators should be put forth. 


\section{An Analytical Framework for the Study of Survey Answers and the Measurement of Radical Uncertainty}

\subsection{Theoretical Tool}

A main purpose of the business tendency surveys is the desire to investigate how opinions, expectations and, in sum, the considered phenomena vary over time. Indeed, these surveys are repeated regularly precisely because understanding of such variation is the goal; in the absence of change, a single survey would suffice to photograph the situation once and for ever. It is therefore of paramount importance to derive, from the various answers of the interviewed subjects, the largest amount and the best quality of information possible regarding changes in opinions, expectations and other relevant behaviours. But this exigency does not seem properly fulfilled by the current uses of the data provided by the European Union surveys. One (of several) consequences of this failure is that an important possibility of measuring true or radical uncertainty is obscured from view. What we shall see, in fact, is that the volatility of opinions and the difference between expectations and results as expressed by the Business Tendency Surveys and usually disregarded can be interpreted as a measure of radical uncertainty and, once noted, may facilitate the investigation of the important effects of uncertainty on entrepreneurial and economic behaviour, specifically with regard to the business cycle. Such a measure would very likely prove itself to be one of the most profitable uses of the surveys, which are harmonized in all EU countries and thereby provide precious homogeneous data series.

A useful starting point of the analysis is a matrix assembling the survey results of two periods. The rows and columns of the matrix refer to the first and second periods respectively and express the modalities of answer (Up, Same, Down, indicated respectively by the subscripts $1,2,3)$. The matrix is as follows:

Table 1. Survey answers of two periods

\begin{tabular}{llcclll}
\hline \multicolumn{1}{l}{ Total } & $\mathrm{Y}_{1}$ & $(\mathrm{UP})$ & $\mathrm{Y}_{2}$ & $(\mathrm{SAME})$ & $\mathrm{Y}_{3}$ & (DOWN) \\
\hline $\mathrm{X}_{1}$ & $(\mathrm{UP})$ & $\mathrm{R}_{11}$ & $\mathrm{R}_{12}$ & $\mathrm{R}_{13}$ \\
$\mathrm{X}_{2}$ & (SAME) & $\mathrm{R}_{21}$ & $\mathrm{R}_{22}$ & $\mathrm{R}_{23}$ \\
$\mathrm{X} 3$ & (DOWN) & $\mathrm{R}_{31}$ & $\mathrm{R}_{32}$ & $\mathrm{R}_{33}$ \\
\hline
\end{tabular}

$\mathrm{X}$ expresses the per cent of each modality of answer (on total answers) in the first period and $\mathrm{Y}$ the same percent in the second period. $R_{i j}$ with $i=j$, that is, the terms on the main diagonal, indicate, for each modality, the percentage of answers that do not change from one period to another. The remaining $R_{i j}(i . e$. with $i \neq j$ ) express the percentage of answers changing from modality $\mathrm{i}$ in the first period to modality $\mathrm{j}$ in the second period.

The current publications on the survey data show only the total by row (X) and column (Y) and the balance (Up minus Down), while the intermediate terms of the matrix (the transition from modality $i$ to $j$ ) are absent. But the intermediate terms are indispensable for representing the changes in answers; in fact, the total of each modality hides changes over time by compensation.

\subsection{Indicators of Radical Uncertainty}

The matrix data allow the computation of some useful indicators, such as the volatility of opinions (or of results), that is, the sum of the terms of the matrix outside the main diagonal; in fact, that sum can be interpreted as an important indicator of radical or true uncertainty. The indicator can be formalised as follows:

$$
\mathrm{OV}=\Sigma_{\mathrm{t} 0}{ }^{\mathrm{t} 1} \mathrm{R}_{\mathrm{ij}} \quad \text { with } \mathrm{i} \neq \mathrm{j}
$$

OV stands for opinions' (or results') volatility (Note 4).

The reference to opinions and expectations stresses the need to measure their volatility. But also the volatility of the answers concerning results, not considered by the applications in this paper, may be important under other respects. To this measure of uncertainty based on the volatility of opinions it might be objected that, by the time a new state of the world arises, thus making the change of opinion no longer a signal of uncertainty. This objection is based on a clear misunderstanding. In formulating expectations, one uses the information that one has on the state of the world; when information and/or opinions change, due to changes in the state of the world or for other reasons, new expectations will be formulated, but without the achievement of certainty - such a goal being but a chimera. It is quite natural to refer uncertainty of opinions to the volatility of opinions, i.e. their 
variability, whatever their accuracy (and whatever the causes of their variability), that is, independently of the fact that, for example, the opinions and expectations of survey period 1 turn out to be more accurate than those of period 2. As a simple matter of fact, respondents can be very uncertain about expectations that turn out to be accurate.

We do not deny that a proxy of uncertainty based on the volatility of opinions has its limitations, as does any kind of empirical analysis. In fact, the phenomena considered by the surveys do not cover all the causes of uncertainty. To partly remedy this, a second indicator has been provided through a direct question. Specifically, starting from April 2004, and on my request, an additional question was included in the ISAE (Note 5) quarterly business surveys: "In the last months, what proportion of your expectations on some main variables (demand and delivery orders, profit, variable costs) was confirmed?"

There exist some differences as well as analogies between the first (indirect) and the second (direct) indicators of uncertainty. While the first indicator expresses the volatility of expectations, the second expresses the effective violation of expectations. An evident linkage between the two indicators is that the non-confirmation of expectations, expressed by the second indicator, may cause changes in expectations and hence in the first indicator.

We can identify a third indicator of uncertainty in the standard deviation of profit rates across firms. In an economy of perfect knowledge and in the absence of institutional monopolies, such deviations would be null. It is the existence of limits to knowledge (true uncertainty) that allows differentials in capabilities and the associated profits to rise. This seems to imply that the variance of profit rates across firms provides an expression of the limits of knowledge, that is, of uncertainty. As we shall see, this indicator is suitable to the representation of dynamic competition processes and business cycles (Note 6).

Our transition matrix of survey answers allows the derivation of some other useful indicators. It is worthwhile dedicating some attention to what can be called a 'permanence indicator'. Clearly, the answers resulting from very fragile opinions (that is, opinions much subject to change) are less meaningful than those resulting from less volatile opinions. This is not a question of mere reliability. The permanence of respondents' opinions (or their volatility) may be right or wrong; the point, however, is that if a respondent is, for instance, wrongly convinced of something, he operates accordingly; conviction (in doing something) represents, therefore, a relevant item of information for understanding his behaviour. This underlines the importance of an indicator of the degree of permanence of answers; which can be expressed as follows:

$$
\operatorname{Perm} U p=R_{l l}{ }^{(t 0: t l)} / U p^{(t l)}
$$

This gives the proportion of the answers saying Up that do not change from period $t_{0}$ to $t_{1}$, on the percent of Up relative to period $t_{1}$. Of course, the permanence indicator for Same and Down must substitute in the expression 1, respectively, $R_{22}$ and $R_{33}$ to $R_{11}$, and Same or Down to Up. These indicators can be used to weight the current percent of Up, Same and Down, in order to obtain some new values for each modality that take into account the degree of insistence on answers; such insistence expressing any one particular marked direction of firms' expectations and opinions.

A stronger way to compute the persistence indicator is the following:

$$
\operatorname{Perm} U p=\left(R_{I I}{ }^{(t): t l)}+2 R^{\prime \prime}{ }_{11}^{(t l: t 2}\right) / 3 U p^{(t l)}
$$

where $\mathrm{R}_{11}$ represents the portion of the $\mathrm{R}_{11}$ that does not change also in the period $\mathrm{t}_{1}: \mathrm{t}_{2}$ or, in other words, the percentage of respondents that give the same answer in three consecutive surveys (we attribute a double weight to R"). The expression of the permanence indicator for Same and Down is identical, with the due changes in R and the denominator (Note 7).

Also an average of two consecutive periods may be considered; that is:

$$
\operatorname{Perm} U p=\left(R_{l l}{ }^{(t 0: t l)}+R_{l l}{ }^{(t l: t 2)}\right) / 2 U p^{(t l)}
$$

A different weight may be attributed to the $\mathrm{R}$ of the two periods.

\section{Evidence from the Business Surveys}

\subsection{Uncertainty and the Size of the Firm}

1). The results that follow refer to the volatility indicator OV and have been derived from the answers to the EU-ISAE monthly surveys of business tendency and conditions for a sample of firms that are representative of all industrial sectors and Italian geographical areas. The answers refer to expectations over the next three or four months, discounted by all seasonal factors and concern: delivery orders, production, prices, cost of financing and 
liquidity assets. These variables are defined by three modalities: modality 1, expressing "increase" (in the rate of change of the variables), modality 2 , indicating "no change", modality 3 , expressing "decrease".

The EU-ISAE business tendency surveys report the number of persons employed by each firm, so the indicator of uncertainty derived from them can be distinguished according to the size of the firm. This provides for some important information. For instance, if the firm's behaviors and organization is influenced by uncertainty, then we can ask whether this uncertainty varies according to size. We have grouped firms by size into six classes. The first class (up to 15 employees) intends to show the influence of uncertainty on dimensional growth beyond the threshold that marked the effectiveness of the Italian Working People Statute. We consider here un-weighted answers since the attribution of the same weight to each opinion gives a better expression of the state of opinions than answers weighted according to the size of the firm. The average (of each column) for the whole period is shown, providing a clear idea of the standard deviation (from the average) over the period considered.

The monthly data have been aggregated by year and computed starting from 1986. But the tables below start from 1998, when some modifications in the survey generate a discontinuity, and terminate in 2005 for the same reason.

Table 2. Uncertainty on production (Relative change of answers based on previous month)

\begin{tabular}{lcccccc}
\hline \multirow{2}{*}{ Years } & \multicolumn{6}{c}{ Size of firm } \\
\cline { 2 - 7 } & $1-15$ & $16-99$ & $100-249$ & $250-324$ & $325-499$ & 500 and above \\
\hline 1998 & 0.385 & 0.345 & 0.325 & 0.342 & 0.334 & 0.292 \\
1999 & 0.389 & 0.35 & 0.335 & 0.339 & 0.34 & 0.306 \\
2000 & 0.395 & 0.358 & 0.333 & 0.296 & 0.316 & 0.274 \\
2001 & 0.405 & 0.379 & 0.366 & 0.406 & 0.323 & 0.322 \\
2002 & 0.373 & 0.35 & 0.343 & 0.38 & 0.33 & 0.274 \\
2003 & 0.402 & 0.378 & 0.347 & 0.345 & 0.341 & 0.304 \\
2004 & 0.4 & 0.378 & 0.35 & 0.345 & 0.365 & 0.292 \\
2005 & 0.386 & 0.356 & 0.361 & 0.350 & 0.325 & 0.277 \\
Average & 0.391 & 0.362 & 0.345 & 0.350 & 0.334 & 0.293 \\
\hline
\end{tabular}

Table 3. Uncertainty on delivery orders and demand (Relative change of answers based on previous month)

\begin{tabular}{lcccccc}
\hline \multirow{2}{*}{ Years } & \multicolumn{6}{c}{ Size of firm } \\
\cline { 2 - 7 } & $1-15$ & $16-99$ & $100-249$ & $250-324$ & $325-499$ & 500 and above \\
\hline 1998 & 0.395 & 0.355 & 0.329 & 0.331 & 0.325 & 0.279 \\
1999 & 0.399 & 0.357 & 0.335 & 0.339 & 0.333 & 0.289 \\
2000 & 0.398 & 0.362 & 0.334 & 0.329 & 0.318 & 0.288 \\
2001 & 0.412 & 0.388 & 0.374 & 0.405 & 0.353 & 0.332 \\
2002 & 0.385 & 0.359 & 0.357 & 0.39 & 0.34 & 0.296 \\
2003 & 0.413 & 0.391 & 0.360 & 0.369 & 0.357 & 0.311 \\
2004 & 0.408 & 0.386 & 0.355 & 0.337 & 0.376 & 0.276 \\
2005 & 0.4 & 0.367 & 0.353 & 0.378 & 0.351 & 0.265 \\
Average & 0.401 & 0.370 & 0.349 & 0.359 & 0.344 & 0.292 \\
\hline
\end{tabular}


Table 4. Uncertainty on prices (Relative change of answers based on previous month)

\begin{tabular}{lcccccc}
\hline \multirow{2}{*}{ Years } & \multicolumn{6}{c}{ Size of firm } \\
\cline { 2 - 7 } & $1-15$ & $16-99$ & $100-249$ & $250-324$ & $325-499$ & 500 and above \\
\hline 1998 & 0.186 & 0.209 & 0.211 & 0.261 & 0.242 & 0.229 \\
1999 & 0.212 & 0.22 & 0.210 & 0.221 & 0.205 & 0.164 \\
2000 & 0.294 & 0.293 & 0.261 & 0.295 & 0.27 & 0.243 \\
2001 & 0.25 & 0.245 & 0.217 & 0.256 & 0.246 & 0.215 \\
2002 & 0.181 & 0.186 & 0.196 & 0.151 & 0.239 & 0.181 \\
2003 & 0.196 & 0.212 & 0.222 & 0.192 & 0.216 & 0.188 \\
2004 & 0.195 & 0.200 & 0.196 & 0.17 & 0.179 & 0.169 \\
2005 & 0.176 & 0.174 & 0.172 & 0.162 & 0.176 & 0.193 \\
Average & 0.211 & 0.217 & 0.210 & 0.213 & 0.221 & 0.198 \\
\hline
\end{tabular}

Table 5. Uncertainty on cost of financing (Relative change of answers based on previous month)

\begin{tabular}{lcccccc}
\hline \multirow{2}{*}{ Years } & \multicolumn{6}{c}{ Size of firm } \\
\cline { 2 - 7 } & $1-15$ & $16-99$ & $100-249$ & $250-324$ & $325-499$ & 500 and above \\
\hline 1998 & 0.317 & 0.306 & 0.301 & 0.317 & 0.316 & 0.229 \\
1999 & 0.276 & 0.284 & 0.257 & 0.281 & 0.229 & 0.195 \\
2000 & 0.338 & 0.323 & 0.294 & 0.309 & 0.242 & 0.242 \\
2001 & 0.336 & 0.315 & 0.287 & 0.294 & 0.249 & 0.217 \\
2002 & 0.271 & 0.260 & 0.246 & 0.235 & 0.225 & 0.191 \\
2003 & 0.324 & 0.304 & 0.282 & 0.281 & 0.251 & 0.207 \\
2004 & 0.315 & 0.277 & 0.237 & 0.216 & 0.211 & 0.173 \\
2005 & 0.296 & 0.244 & 0.192 & 0.198 & 0.162 & 0.107 \\
Average & 0.309 & 0.289 & 0.262 & 0.266 & 0.235 & 0.195 \\
\hline
\end{tabular}

Table 6. Uncertainty on liquidity assets (Relative change of answers based on previous month)

\begin{tabular}{lcccccc}
\hline \multirow{2}{*}{ Years } & \multicolumn{5}{c}{ Size of firm } \\
\cline { 2 - 7 } & $1-15$ & $16-99$ & $100-249$ & $250-324$ & $325-499$ & 500 and above \\
\hline 1998 & 0.317 & 0.281 & 0.26 & 0.284 & 0.262 & 0.217 \\
1999 & 0.31 & 0.274 & 0.232 & 0.22 & 0.277 & 0.205 \\
2000 & 0.332 & 0.297 & 0.251 & 0.254 & 0.243 & 0.255 \\
2001 & 0.349 & 0.311 & 0.294 & 0.221 & 0.275 & 0.246 \\
2002 & 0.315 & 0.279 & 0.274 & 0.245 & 0.236 & 0.222 \\
2003 & 0.351 & 0.314 & 0.262 & 0.261 & 0.282 & 0.241 \\
2004 & 0.361 & 0.311 & 0.259 & 0.204 & 0.248 & 0.213 \\
2005 & 0.355 & 0.304 & 0.247 & 0.194 & 0.257 & 0.196 \\
Average & 0.336 & 0.296 & 0.260 & 0.235 & 0.260 & 0.224 \\
\hline
\end{tabular}


Table 7. General level of uncertainty, derived by the aggregation of the above series (Relative change of answers based on previous month)

\begin{tabular}{ccccccc}
\hline \multirow{2}{*}{ Years } & \multicolumn{5}{c}{ Size of firm } \\
\cline { 2 - 7 } & $1-15$ & $16-99$ & $100-249$ & $250-324$ & $325-499$ & 500 and above \\
\hline 1998 & 0.32 & 0.299 & 0.285 & 0.307 & 0.296 & 0.249 \\
1999 & 0.317 & 0.297 & 0.274 & 0.28 & 0.277 & 0.232 \\
2000 & 0.351 & 0.326 & 0.295 & 0.297 & 0.278 & 0.260 \\
2001 & 0.35 & 0.328 & 0.307 & 0.317 & 0.289 & 0.267 \\
2002 & 0.305 & 0.287 & 0.283 & 0.280 & 0.274 & 0.233 \\
2003 & 0.337 & 0.32 & 0.295 & 0.290 & 0.290 & 0.250 \\
2004 & 0.336 & 0.310 & 0.286 & 0.254 & 0.276 & 0.225 \\
2005 & 0.323 & 0.289 & 0.265 & 0.256 & 0.254 & 0.208 \\
Average & 0.330 & 0.307 & 0.286 & 0.285 & 0.279 & 0.240 \\
\hline
\end{tabular}

As we can see, uncertainty (as expressed by the indicator considered) varies inversely with the size of firms and is around 0.2 and 0.4. The high level of uncertainty of the first two classes (1-15 and 16-99 employees) means that expansion over the threshold of 15 employees is discouraged, since it implies an increase in normative rigidities while uncertainty remains high.

Uncertainty decreases with increase in firms' size in the first three classes shows some ambiguity in the two central classes, and decreases substantially in the largest class. In particular, increase in size of firms significantly reduces the variability of expectations on cost of financing, and this, together with the parallel reduction of uncertainty on liquidity assets, should encourage dimensional expansion.

The uncertainty on prices is less than on other variables; it is particularly low in the largest class of firms, probably due to oligopoly, and lower than expected in the first class, probably owing to market niches.

2). It may be useful to add some data on the second (direct) indicator of uncertainty which, it will be recalled, expresses the effective violation of expectations. For reasons of space, we limit ourselves to a graphic comparison of the two indicators. Figures 1 and 2 below refer, respectively, to the first and the second indicator; full-lines indicate small firms, semi-dotted lines indicate medium-sized firms and dotted-lines indicate large firms. Figure 1 shows quarterly data from April 2004 to (only) October 2005 (as the computation of this indicator is disturbed in 2006 by a jump in the modality of survey). Figure 2 shows twelve quarterly data, from April 2004 to January 2007.

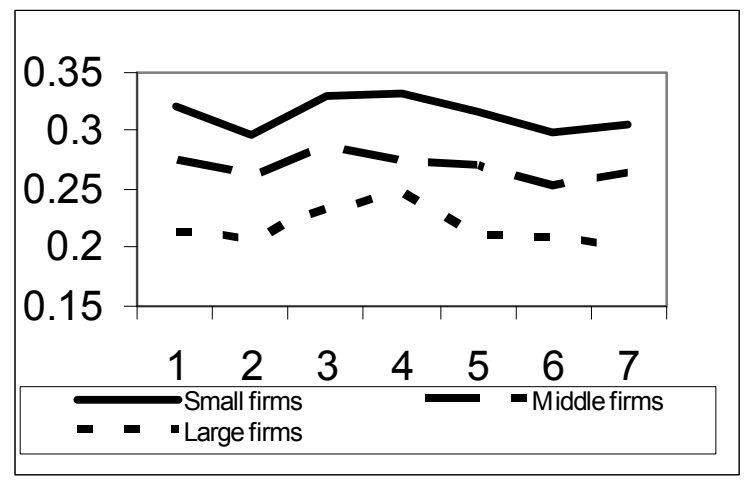

Figure 1. 1st indicator of uncertainty by classes of business size 


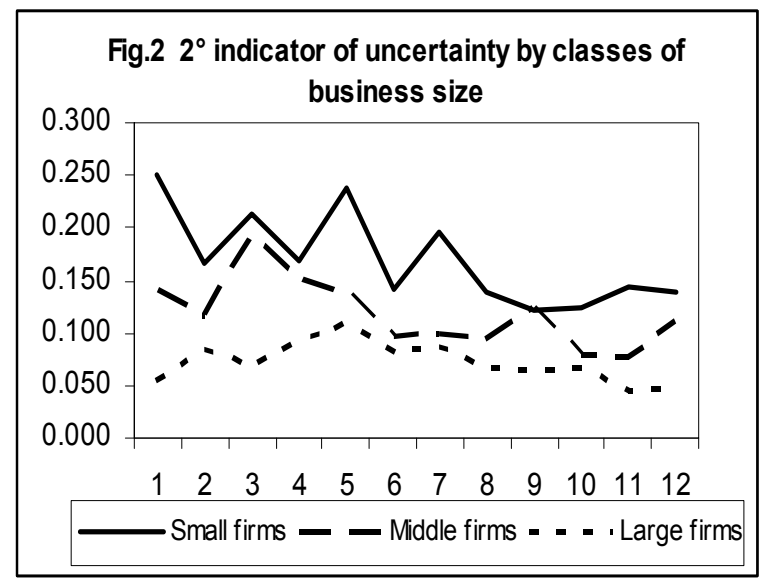

Figure 2. 2nd indicator of uncertainty by classes of business size

The second graph is more uneven than the first, probably due to the absence of deseasonalization (made impossible by the smaller amount of data) and to the fact that the revision of expectations is slower than their violation. Uncertainty appears to be lower in figure 2, since this only considers the modality "low confirmation" of expectations, due to the absence of weights attributed to the modalities "high confirmation" and "middle confirmation". However, in both figures uncertainty markedly decreases with increase in business size. The inverse relation between uncertainty and firms' size is thus confirmed; this is relevant for firms' transaction costs, financing and innovation, as these are greatly influenced by uncertainty.

3). Finally, it may be useful to provide three figures illustrating the indirect indicator of uncertainty derived from the expectations-realizations difference of the ISAE monthly surveys. The graphs show the percentage of expectations in period $t$ that differ from the realizations relative to one, two and three months later. Unfortunately, in recent years the survey questions on results have been limited by ISAE to only liquidity assets and production, and this of course reduces the possibility of confrontation between expectations and results. The confrontation considered here refers to the year 2004. The six classes of size are indicated on the $\mathrm{x}$ axis.
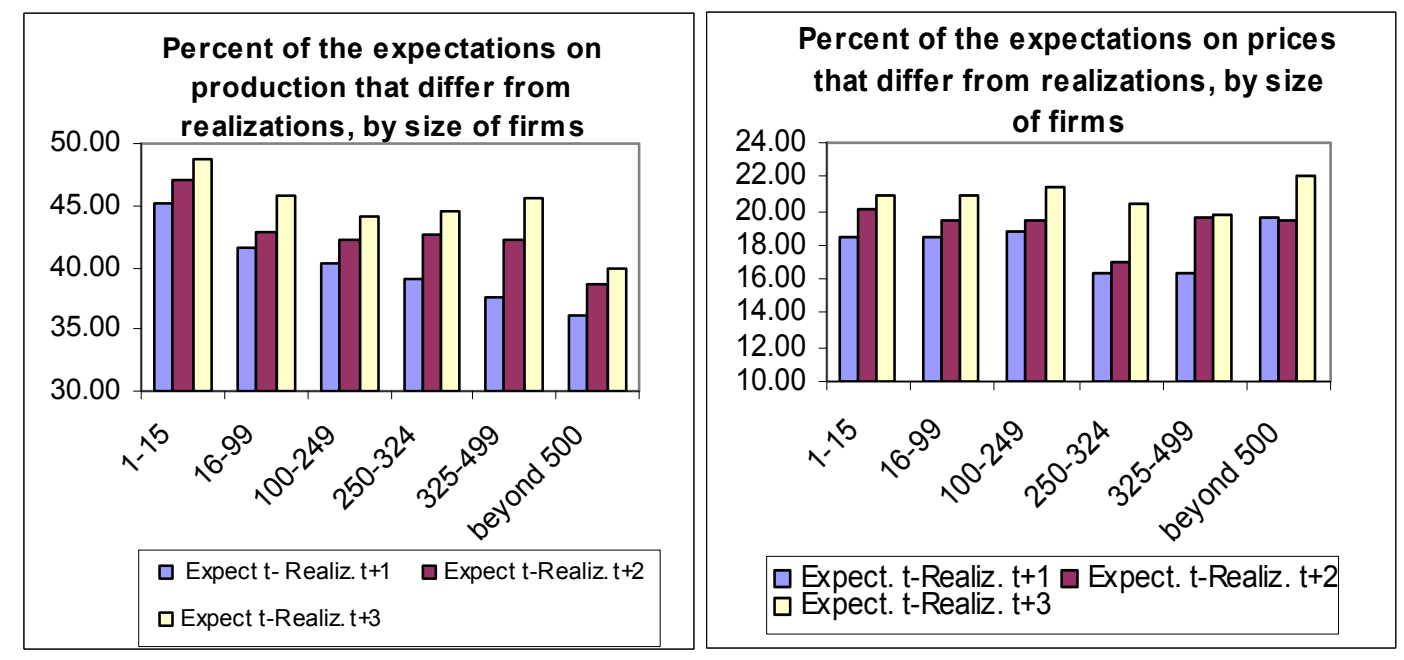


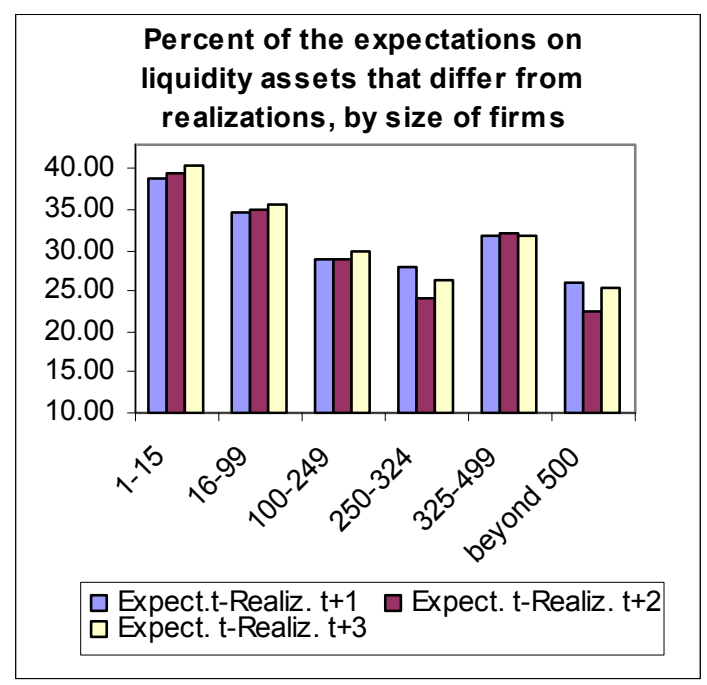

Figure 3. Expectations-realizations differences

This indicator of uncertainty based on the difference between expectation and realization substantially confirms the results derived from tables 2, 4 and 6, except that uncertainty on prices in the last class is higher than expected. It also appears that the difference between expectations and realizations grows with the time distance between the two, but with some exception for liquidity assets.

\subsection{Business Confidence Indicator Corrected for Uncertainty}

Our research on a measure of the degree of uncertainty leads us to some reflections upon the business confidence indicator currently derived from the monthly business tendency surveys (BTS). This indicator is the result of an arithmetical average of the balances of answers (difference between Up and Down) concerning three phenomena: current overall delivery orders, the stock of finished products, expectations on production. Such computation does not consider uncertainty; in fact, expectations on production cannot be considered a proxy of uncertainty, which is rather expressed by the volatility of expectations, as previously seen in section 3 .

Of course, uncertainty influences the degree of confidence more than do any of the three phenomena usually considered in the standard computation of the business confidence indicator. It may, therefore, be interesting to compare between the current confidence indicator and our indicator of uncertainty. Both the indicators have been expressed in quarterly values, with 2000 the year base.

In figure 4 below, the dotted-line stands for the usual confidence indicator while the full-line stands for the uncertainty indicator.

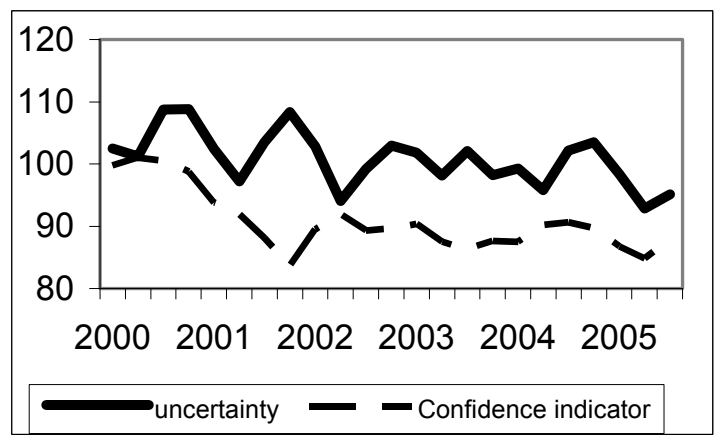

Figure 4. Radical uncertainty and confidence indicator

As can be seen, the behaviour of uncertainty differs markedly from that of the usual confidence indicator; it is in general higher and more uneven. This means that the possible introduction of uncertainty in the computation of the confidence indicator would lead to some remarkable changes with regard to the current computation of the indicator. This is shown in figure 5. This figure compares the usual confidence indicator to an indicator that is 
derived by adding radical uncertainty with a weight of 0.25 , and hence attributing to the usual indicator a weight of 0.75 . The working hypothesis is that each one of the four components has an identical importance; although it is our actual opinion that a higher weight should be attributed to uncertainty. Of course, the influence of uncertainty on the confidence indicator is negative.

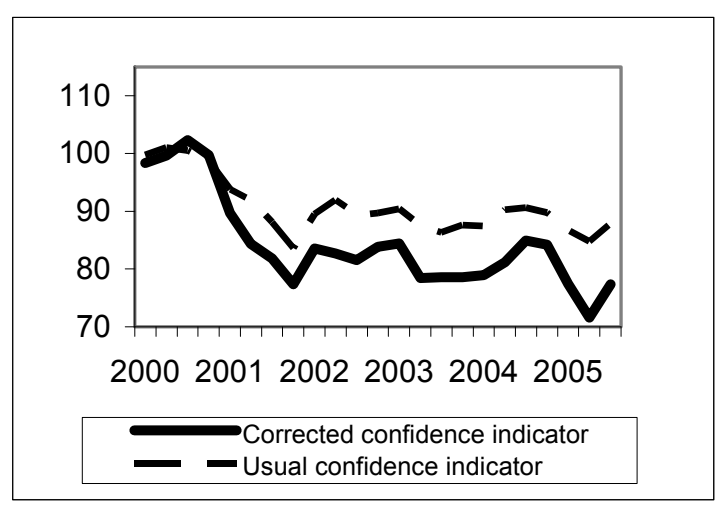

Figure 5. Usual confidence Indicator and that corrected by radical uncertainty

The figure shows substantial differences between the two indicators. Since in figure 4 the uncertainty indicator was above the usual confidence indicator, the new confidence indicator shown in figure 5 is lower than the usual one. The moderate weight of uncertainty in the computation of the new confidence indicator prevents higher differences between the time paths of the two.

It can be objected that the weight we have attributed to uncertainty in our hypothetical revision of the confidence indicator is arbitrary. But the attribution of identical weights to the three survey questions - which is used for the definition of the current confidence indicator - is also arbitrary. An approach to dealing with the question of weight attribution might be econometric testing. Here we set out some estimation of the relation between industrial production, volatility and the usual confidence indicator. The results are not completely satisfactory but nevertheless warrant some attention. They seem to suggest a deepening of the analysis on the confidence indicator and its components.

The following differential adjustment equation has been estimated:

$$
\begin{aligned}
& \mathrm{DIP}=\alpha(\hat{\mathrm{IP}}-\mathrm{IP}) \\
& \hat{\mathrm{IP}}=\beta_{1} \mathrm{CI}-\beta_{2} \mathrm{OV}
\end{aligned}
$$

where:

$$
\begin{aligned}
& \mathrm{IP}=\text { Variation of the index of industrial production } \\
& \mathrm{CI}=\text { Usual confidence indicator } \\
& \mathrm{OV}=\text { Opinions' volatility } \\
& \mathrm{D} \text { is the derivative with respect to time } \\
& \alpha \text { is an adjustment parameter }
\end{aligned}
$$

The estimate uses data concerning Italy (Note 8). Monthly survey data have been used, from February 2000 to April 2011. Industrial production does not show a trend component and hence does not require filtering (Hodrick-Prescott or other filters) for eliminating such a trend.

The results are

$\begin{array}{ll}\text { Parameters } & \text { t-values } \\ \alpha=2.969 & 5.69 \\ \beta_{1}=2.328 & 1.4 \\ \beta_{2}=0.946 & 1.38\end{array}$

Carter-Nagar $\mathrm{R}^{2}=0.60$ 
All parameters show the right sign. The above results consider raw IP data; $\mathrm{CI}$ is taken by the ISAE balances and is not deseasonalised.

In order to see the degree of significance and contribution of each component, an econometric analysis of the relations between the components of the confidence indicator and the variation of industrial production may be performed, which includes also volatility in the regression. An estimation in this regard using non-deseasonalised values has shown wrong signs, both for the current overall orders and the current stock of finished products; only expectations on production and volatility seem to have an explanatory meaning. Carter-Nagar $\mathrm{R}^{2}$ is 0.73 . This seems to show the importance of the need for a wider inquiry on the definition of the confidence indicator, i.e. an inquiry that also takes into account some other survey questions.

4.3 Some Applications Concerning the Permanence Indicator and the Corrections of Up, Same and Down by Giving a Double Weight to $R_{i i}$ (The Repeated Answers) (Note 9)

The results that will follow concern three questions of the harmonised EU surveys, two of which express opinions and one expresses expectations. The questions are: a) Do you consider current overall order to be above normal, normal for the season, below normal? b) Do you consider your current stock of finished products to be above normal, normal for the season, below normal? c) How do you expect your production to develop over the next 3 months? It will increase, remain unchanged, decrease? The attention for those questions has been suggested by the importance that the European Commission attributes to them that in fact are used to provide the Industry Confidence Indicator for each State member of the European Community and the whole European Union. It seems evident that the dynamics of opinions is better expressed by un-weighted survey data, as these give an identical importance to each answer and opinion.

An analogous application was performed on data for South Africa provided by Murray Pellissier and concerning four questions of the BER surveys on expectations. The results confirmed those reported below.

The figures that follow flank, to the EU surveys results, those 'modified' or corrected according to the weight attributed to $\mathrm{R}_{\mathrm{i} i}$, i.e. the repeated answers. Here we give to these answers a double weight with respect to Up- $\mathrm{R}_{11}$, i. e. the remaining ones. Therefore, the expression for the corrected (or modified) UP is:

$$
\text { Modified } U p=\left(2 R_{I I}+U p-R_{l l}\right) / 3 \text {, that is: }\left(U p+R_{l l}\right) / 3
$$

Of course, the correction of Same and Down must substitute, in the above expression, Same or Down to Up and $\mathrm{R}_{22}$ or $\mathrm{R}_{33}$ to $\mathrm{R}_{11}$ (Note 10 ).

For making comparable the current percent of answers to their modified percents, the sum of the percent of the modified Up, Same and Down has been reported to 100 (i.e. the sum of the current percent modalities of answers) simply by dividing 100 by the sum of the percent of all modified answers and multiplying by the percent of each modified answer (Note 11), i.e. according the proportion Modified Up: $x=\operatorname{modified}(U p+S a m e+D o w n)]: 100$, as well as for Same and Down.

The figures report:

a) The permanence indicator, the first expression for PermUp (Same and Down) in section 3, i.e. a ratio the variability over time of which expresses the discrepancy between the time path of the percentage of the repeated answers (not considered by the current computations on surveys) and the total percent of the corresponding answers (Up or Same or Down); it gives, therefore, an idea of the relevance of the correction we propose.

b) The ratio between the modified percent of answers and the usual percent of answers. The difference (positive or negative) with respect to one of this ratio expresses the percentage of correction, i.e. the percent difference between the modified and current percentages.

c) The ratio $\left(\mathrm{R}_{11}-\mathrm{R}_{33}\right) /$ balance, that gives the variation over time of the difference of the percent of the repeated Up and Down (that we use for corrections) with respect to Up minus Down, i.e. the usual balances. This ratio gives an idea of the impact on balances of our correction. Such correction is plainly expressed by the ratio between the modified balance and the usual one: (ModifiedUp-ModifiedDown)/(Up-Down), i. e. ModifiedBalance/Balance.

In the figures, the variable sub a) is indicated by the permanence indicators $R_{11} / U p ; R_{22} / S a m e ; R_{33} / D o w n$. The variable sub b) is indicated by the ratios ModifiedUp/Up, ModifiedSame/Same; ModifiedDown/Down. The variables sub c are indicated, as we said, by $\left(\mathrm{R}_{11}-\mathrm{R}_{33}\right) /$ balance and ModifiedBalance/balance.

A constant of 100 has been added to $\mathrm{R}_{11}-\mathrm{R}_{33}$, Balance and modified balance in order to avoid negative numbers that would make meaningless the ratios under c, i.e. $\left(\mathrm{R}_{11}-\mathrm{R}_{33}\right) /$ balance and ModifiedBalance/Balance 
The data concern 11 years or, more precisely, 135 monthly periods of survey, starting from February 2000.
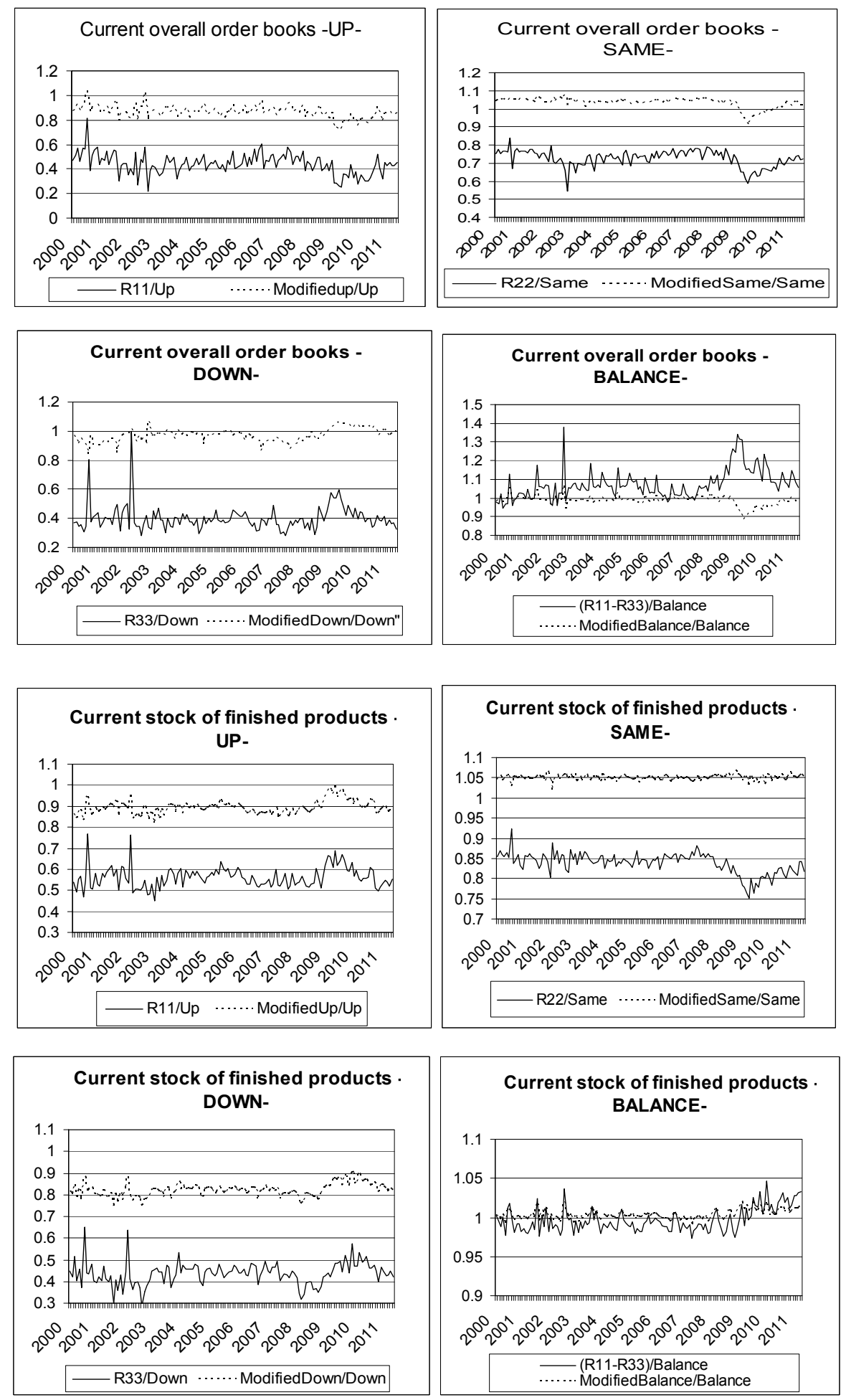

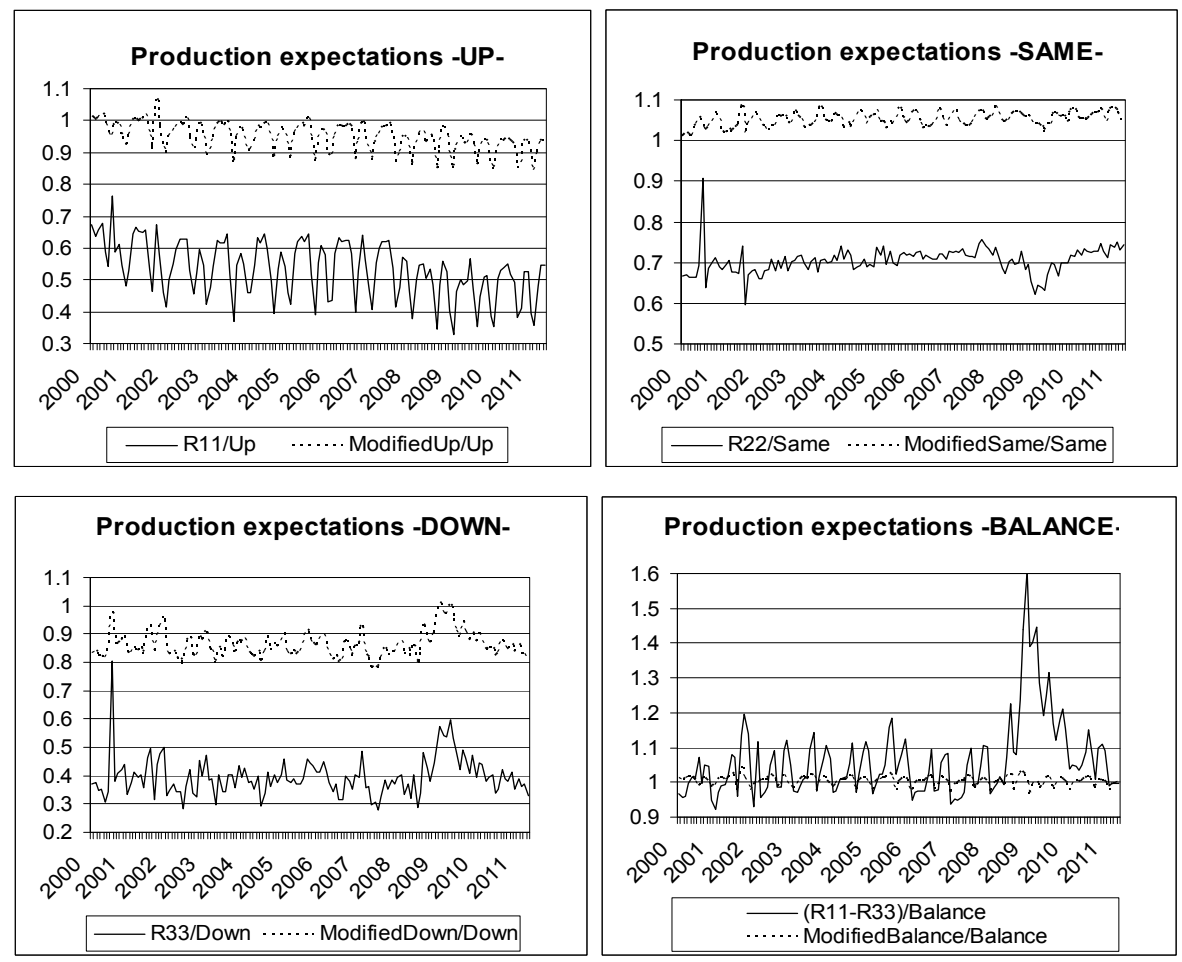

\section{Production expectations -BALANCE.}

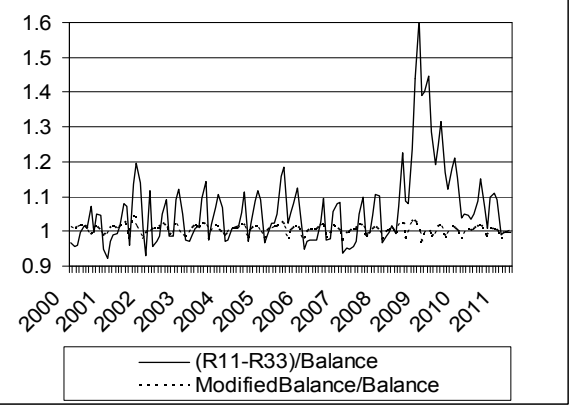

Figure 6. Modified indicators and answers compared to current ones

From the figures we can see substantial differences between the UE surveys values and the modified ones (that is attributing a double weight to the repeated answer $\mathrm{R}$ with respect to the remaining one, non repeated); but a higher weight of the repeated answers used for the rectification would imply larger differences. The percent correction (dotted lines) is lower than the oscillation of the permanence indicators and the ratio $\left(\mathrm{R}_{11}-\mathrm{R}_{33}\right) /$ balance (full lines) since the first also includes the remaining (non permanent) answers that do not contribute to the correction.

In particular, in the first and third Figures (for Up and Down), the correction percentage oscillates around 20 percent, but with a substantial dispersion as an effect of the high dispersion of $\mathrm{R}_{11} / \mathrm{Up}$ and $\mathrm{R}_{33} /$ Down (respectively between $0,8 \quad 0,2$, and $0,8 \quad 0,4)$. The second Figure shows a correction percentage higher than 1 due to the higher value of $R_{22} /$ Same than those of $R_{11} / U p$ and $R_{33} /$ Down. The dispersion is lower than in the first and third Figures since $R_{22}$ /Same is much less uneven than $R_{11} / U p$ and $R_{33} /$ Down.

Figures from the fifth to the eighth (for current stock of finished products) and from the ninth to the twelfth (for production expectations) do not show substantial differences with respect to the behaviour above.

\section{Uncertainty, Innovation and Business Cycle}

\subsection{Dynamic Competition: The Crucial Role of Uncertainty}

The primary goal of this section is to provide further theoretical and empirical evidence of the importance of a measure of radical uncertainty.

The interaction between innovation and uncertainty is at the heart of the mechanism of growth and development and defines the process of dynamic competition in a Schumpeterian and neo-Austrian sense (Note 12). It is surprising that the two kinds of competition (i.e. Kirzner's market process (Note 13) and Schumpeter's creative destruction) (Note 14) remain separated in the literature despite their evident complementariness. Partly, this is due to the presumption that radical uncertainty cannot be measured or even defined, a presumption that we have widely criticized and challenged in the previous sections.

Dynamic competition is the result of entrepreneurs' adaptive quest for profits as they search for existing profit opportunities arising from disequilibria and uncertainty (neo-Austrian market process), and as they innovatively search for new profit opportunities (Schumpeterian process). There is interaction between both the searches (i.e. adaptation and innovation), with the result depending upon the degree of uncertainty. When uncertainty grows, adaptive (neo-Austrian) competition prevails (i.e. competition directed to the discovery and obtaining of existing 
profit opportunities). This leads to a reduction in uncertainty and market disequilibria, which stimulates innovation: both to recreate profit opportunities and because low uncertainty makes innovation easier. But innovation stimulates uncertainty again. Once some measure of radical uncertainty becomes available, then a combination between Schumpeterian and neo-Austrian teaching on innovation and market process gains in (operative) effectiveness, and we may thereby hope to provide a more complete explanation and quantification of dynamic competition processes (Note 15).

In the estimation, we use, for Italy, as indicator of uncertainty, the volatility of expectations. With reference to the other three countries, we use the indicator of uncertainty represented by the standard deviation of profit rates across firms; this seems to offer a good variable for our analysis of dynamic competition and business cycles since it expresses the dimension of adaptive profit opportunities as connected to limited knowledge and market disequilibria. At the same time, for the econometric application below this is sometimes the only available indicator of uncertainty.

As previously noted, innovation feeds uncertainty and the standard deviation of profit rates across firms as a consequence of the increase in market disequilibria, thus stimulating adaptive competition. But adaptive competition causes the reduction in the standard deviation of profit rates and uncertainty and hence a rise in innovation; and so on, with a cyclical behavior and alternation between innovation and adaptation.

\subsection{A Formal Model}

The specification above suggests the possibility of representing, at the aggregate level, the relation between innovation and disequilibria-uncertainty, as expressed by the notion of dynamic competition, through a Lotka-Volterra predator-prey system, where predation is intended only in formal (not physical) terms. Innovation acts as the prey and uncertainty as the predator, according to the following differential system:

$$
\begin{aligned}
& D P A=b_{1} P A-b_{2} u^{*} P A \\
& D u=-b_{3} u+b_{4} P A^{*} u
\end{aligned}
$$

where:

$\mathrm{PA}=$ Patent applications (intended as an indicator of innovation)

$\mathrm{u}=$ Radical uncertainty, which may be indicated through its measure in Section 3 (the volatility indicator of expectations) or, alternatively, the standard deviation of profit rates across firms

$D=$ Derivative $\mathrm{d} / \mathrm{d}_{\mathrm{t}}$

The asterisk * stands for multiplication

Equation 1 may also include a term DE for the variation of entrepreneurial skill, displaying for innovation (the prey) a propulsive role similar to that of stocking in the predator-prey models used by studies on food chains (Note 16).

The parameter $b_{1}$ is a constant exponential rate of growth of innovation, expressing the autonomous push to innovate due to entrepreneurial aggressiveness; its impact on innovation (DPA) is reduced by the degree of radical uncertainty (volatility of expectations or the standard deviation of profit rates) $u$ that discourages (preys on) innovation (PA) according to parameter $b_{2}$. The parameter $b_{3}$ is an exponential rate of growth of radical uncertainty; the negative sign on $b_{3}$ expresses the compressing effect on radical uncertainty (and/or on the standard deviation of profit rates) arising out of adaptive competition (as stimulated by $u$ ). For its part, $b_{4}$ stimulates $\mathrm{u}$ according to the cross product between predator and prey, where the prey is the dimension of innovation (PA) that feeds uncertainty (volatility and/or the standard deviation of profit rates), i.e. feeds the predator. Precisely, innovation is the field of pasture of radical uncertainty: in the absence of innovation, the term with $b_{4}$ would become null because of the adaptive search for profit. When innovation intensifies, $u$ (the predator) grows, thus causing a contraction in innovation (the prey), and hence the predator, with a cyclical alternation. The system parameters give the dimension of the disequilibrating $\left(b_{1}\right.$ and $\left.b_{4}\right)$ and equilibrating $\left(b_{2}\right.$ and $\left.b_{3}\right)$ push expressed by dynamic competition (this being represented by the combination between innovative and adaptive competition).

It may be useful to underline in this regard that the measures of dynamic competition based on the rapidity of contraction of the standard deviation of profit rates across firms (as, for instance, in D.C. Mueller and others or H. Odagiri) (Note 17) only consider adaptive competition or, more precisely, parameter $b_{3}$ of the above system. They ignore the other parameters and hence give a poor approximation to the intensity of competition and economic dynamism, as dynamic competition consists both in innovation and adaptation-(structural organization). 


\subsection{Econometric Estimation}

The estimation below refers to four main European industrial countries: Italy, the United Kingdom, France and Germany. The data on patent applications and grants are used to express innovation and derive from the Ufficio Italiano Brevetti in the case of Italy, and from the United States Department of Commerce in the other cases. The data on radical uncertainty derives from the UE-ISAE Business Tendency Surveys. The data on the standard deviation of profit rates across firms for France and Germany come from D.C. Mueller (1990), and from H. Odagiri (1994) in the case of the United Kingdom; they refer to some samples of manufacturing firms and, respectively, to the periods 1961-82, 1965-82 and 1964-77. It may be objected that these periods are far from the present. But the estimations are only intended to provide an example of econometric application of our theory. At any rate, for Italy the data on patent applications and uncertainty run from April 2000 to December 2010; they have been aggregated by quarters and deseasonalised.

The data for France give pre-tax profit; those for the United Kingdom and Germany give after-tax profit. Their reliabilities are affected by their derivation from the balance sheets of some firms based on dissimilar and not well-established procedures.

The results shown below must be judged in the light of the deficiencies of the appropriate data series. Nevertheless, confirmation of the theory is encouraging. But the improvement of quantitative analysis in the crucial fields of innovation and dynamic competition needs a great deal of statistical research.

A FIML estimator was used to preserve the tight interaction between (1) and (2) above, i.e. innovation and uncertainty (adaptation), which is a crucial point of the research on dynamic competition presented in this Section. The estimates are derived by an asymptotically exact Gaussian estimator of a differential equation system using discrete data. As there is no equivalent of a just-identified model for non-linear systems, there is no system-wide test such as the Carter-Nagar $\mathrm{R}^{2}$ or likelihood-ratio. In order to give an idea of the efficiency of estimations, the means and standard deviations (not to be confused with the standard deviation of profit rates across firms) of the observed and estimated endogenous variables are also reported.

A system which differs from Volterra (pseudo Volterra form), in that the second equation uses only PA instead of the term PA*u in the right-hand side, has also been estimated. As a matter of fact, it may be assumed that the "reproduction" hypothesis typical of Volterra's study on population plainly operates only in the equation of innovation in that each innovation is strongly influenced by the state of knowledge resulting from previous innovations. In the equation of $\mathrm{u}$, however, it may operate only backwards as large disequilibria and uncertainty stimulate adaptation. This means that in equation 2 the cross product term of Volterra, the encounter between predator and prey, may be replaced by the prey (innovation) only.

Data on patent applications have been divided by thousand, for uniformity of their scale with respect to $u$.

\subsubsection{Italy}

Table 8. Model in Volterra's form

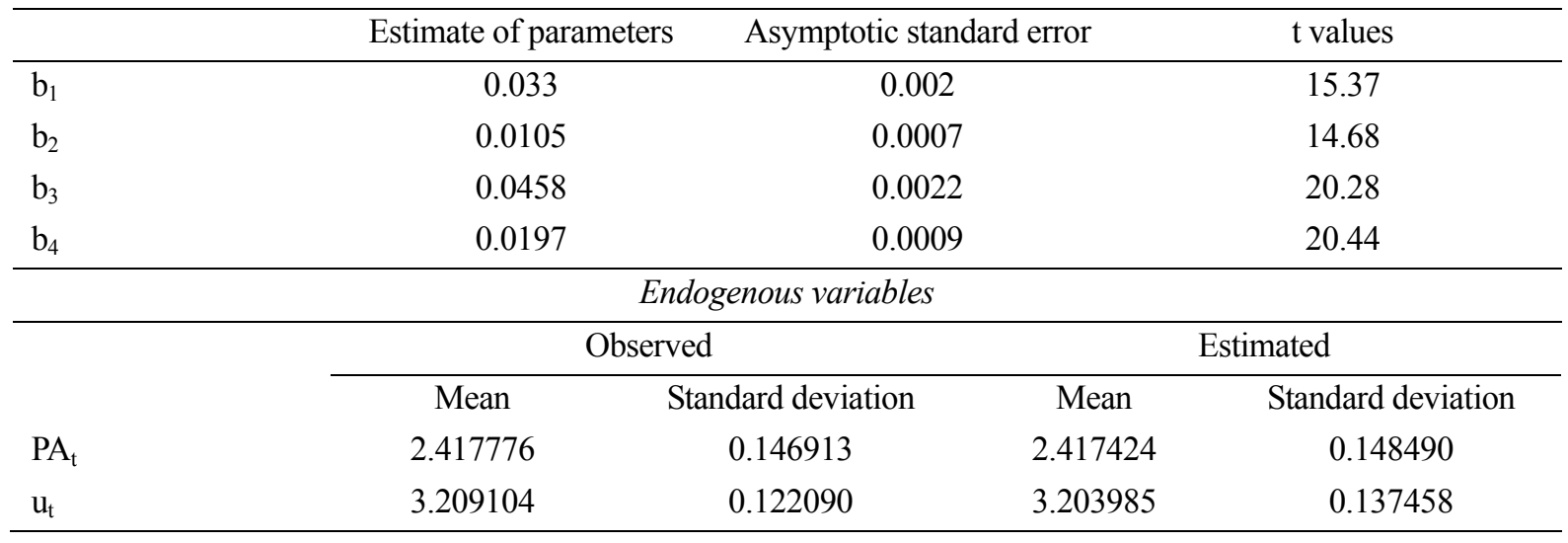




\subsubsection{United Kingdom}

Table 9. Model in Volterra's form

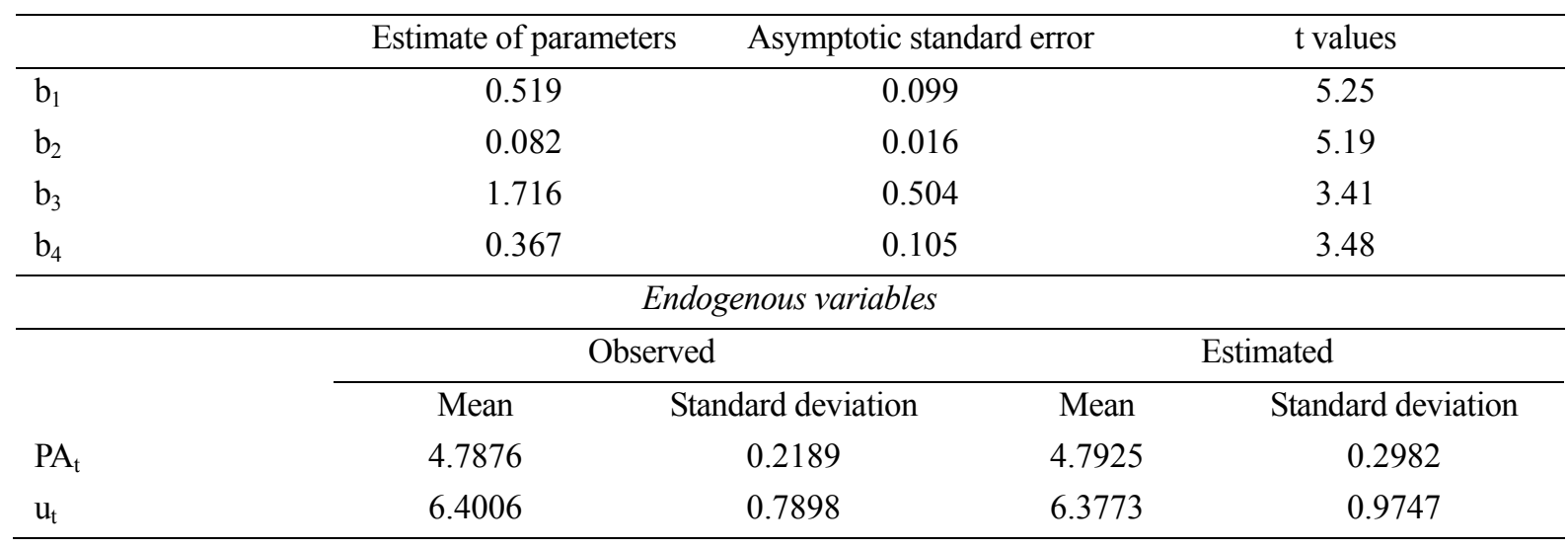

The model with the term PA in equation (2), instead of PA*u, does not converge.

\subsubsection{France}

The data series of the standard deviation of profit rates for France has two out-lying observations in 1974 and 1977. The first has no justification and is probably due to inaccuracy of the data; the second is largely determined by the 1977 revaluations of the assets of mergers that consistently depressed profit rates. We have substituted for those anomalous data an interpolation from the contiguous data (Note 18).

Table 10. Model in Volterra's form

\begin{tabular}{|c|c|c|c|c|}
\hline & Estimate of parameters & \multicolumn{2}{|c|}{ Asymptotic standard error } & $\mathrm{t}$ values \\
\hline $\mathrm{b}_{1}$ & 0.318 & \multicolumn{2}{|c|}{0.121} & 2.61 \\
\hline $\mathrm{b}_{2}$ & 0.048 & \multicolumn{2}{|c|}{0.019} & 2.46 \\
\hline$b_{3}$ & 0.558 & \multicolumn{2}{|c|}{0.244} & 2.29 \\
\hline $\mathrm{b}_{4}$ & 0.192 & \multicolumn{2}{|c|}{0.08} & 2.40 \\
\hline \multicolumn{5}{|c|}{ Endogenous variables } \\
\hline & \multicolumn{2}{|c|}{ Observed } & \multicolumn{2}{|c|}{ Estimated } \\
\hline & \multicolumn{2}{|r|}{ Standard deviation } & Mean & Standard deviation \\
\hline $\mathrm{PA}_{\mathrm{t}}$ & 3.0316 & 0.2261 & 3.0295 & 0.2302 \\
\hline$u_{t}$ & 6.3311 & 0.7627 & 6.3183 & 0.8061 \\
\hline
\end{tabular}

Table 11. Model with the term PA in equation (2), instead of PA*u

\begin{tabular}{|c|c|c|c|c|}
\hline & Estimate of parameters & \multicolumn{2}{|c|}{ Asymptotic standard error } & $\mathrm{t}$ values \\
\hline $\mathrm{b}_{1}$ & 0.252 & \multicolumn{2}{|c|}{0.158} & 1.59 \\
\hline$b_{2}$ & 0.037 & \multicolumn{2}{|c|}{0.252} & 1.48 \\
\hline$b_{3}$ & 0.608 & \multicolumn{2}{|c|}{0.348} & 1.75 \\
\hline $\mathrm{b}_{4}$ & 1.32 & \multicolumn{2}{|c|}{0.722} & 1.83 \\
\hline \multicolumn{5}{|c|}{ Endogenous variables } \\
\hline & \multicolumn{2}{|c|}{ Observed } & \multicolumn{2}{|c|}{ Estimated } \\
\hline & \multicolumn{2}{|c|}{ Standard deviation } & Mean & Standard deviation \\
\hline $\mathrm{PA}_{\mathrm{t}}$ & \multicolumn{2}{|r|}{0.2261} & 3.0263 & 0.2418 \\
\hline$u_{t}$ & 6.2933 & 0.7637 & 6.3072 & 0.5024 \\
\hline
\end{tabular}




\subsubsection{Germany}

Table 12. Model in Volterra's form

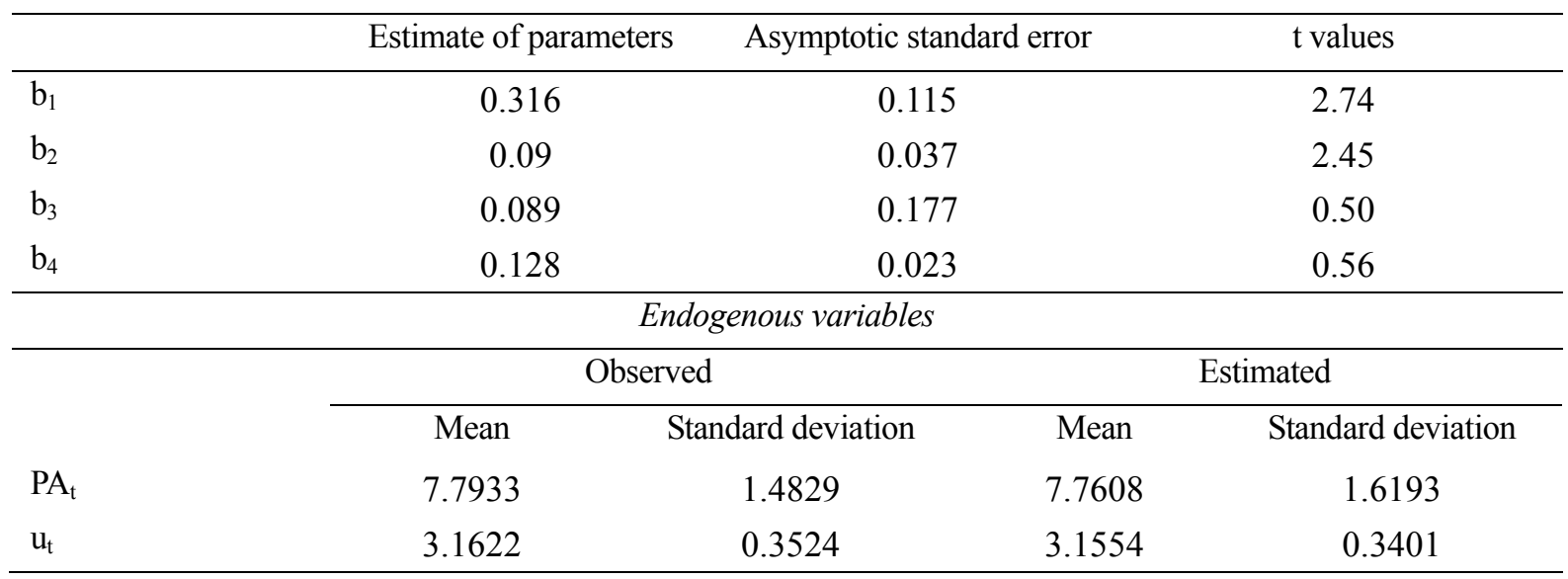

Table 13. Model with the term PA in equation (2), instead of PA*u

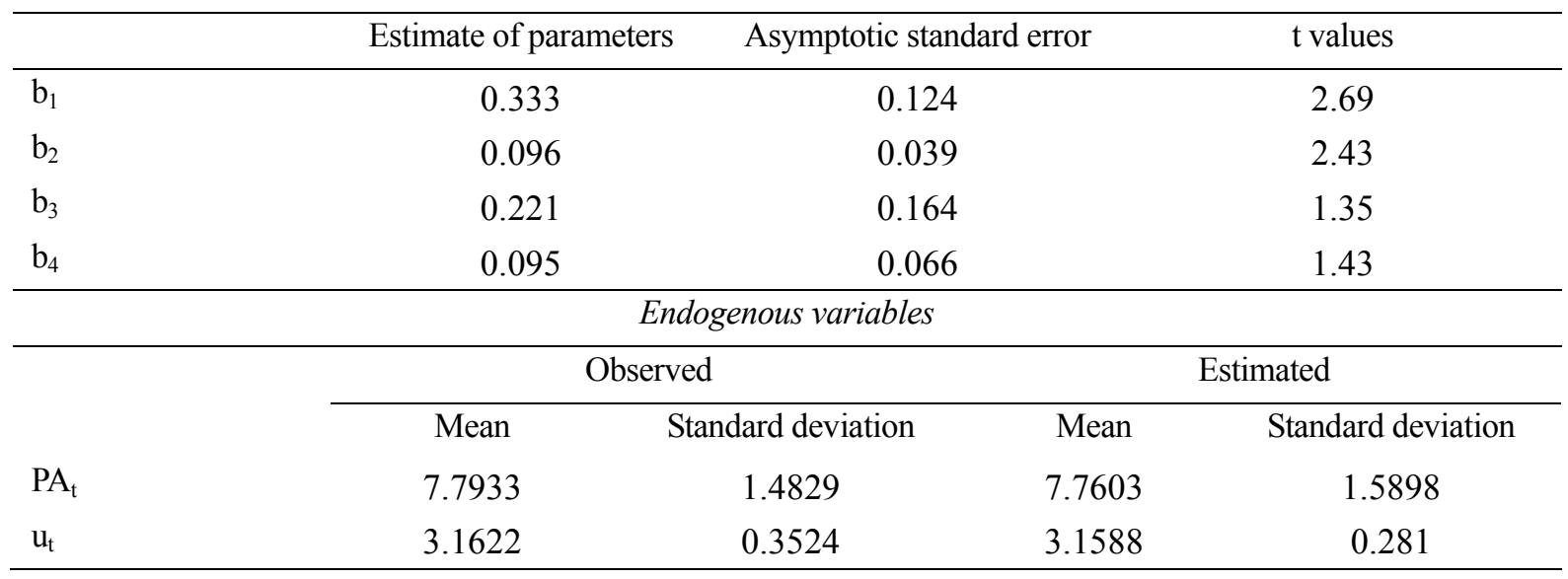

For Italy, the values of parameters are much lower than is the case in the other countries. This is mainly due to the fact that in the recent period the rate of growth of patent applications has substantially decreased and the rate of growth of uncertainty has increased, while in the estimation periods concerning the other countries considered the rate of growth of patent applications was high and uncertainty (the standard deviation of profit rates across firms) decreasing.

For Germany, the model in Volterra's form provides a worse estimate of the equation for $\mathrm{u}$ (the standard deviation of profit rates across firms) than the model where the term PA is substituted for PA*u in (2); the contrary is the case for France and the United Kingdom. It would seem, therefore, that in Germany disequilibria do not generate disequilibria, while a self-reinforcing tendency of disequilibria appears in the United Kingdom and France, i.e. u contributes to stimulate its own growth through the term PA*u.

All parameters have the correct signs, have reasonable values and, in the estimation of the model in the Volterra form for the United Kingdom and France and in the pseudo Volterra form for Germany, are significantly different from zero around the 1 percent level.

The models were also estimated utilizing data on patent grants instead of patent applications, but the results have not been presented as, in all cases, patent applications gave better estimates. This is not surprising since patent applications provide a better expression of the innovative propensity of firms, i.e. their intention to innovate.

It may be interesting to compare the estimated parameters relative to various countries, taking it as given that parameter $b_{1}$ expresses the innovative verve, parameter $b_{3}$ the adaptive push, while parameters $b_{1}$ and $b_{4}$ 
represent the disequilibrating forces and parameters $b_{2}$ and $b_{3}$ express the equilibrating ones.

Italy shows a relevant innovative verve and adaptive push $\left(b_{1}\right.$ and $\left.b_{3}\right)$, meaning a satisfactory degree of dynamic competition, while the disequilibrating and equilibrating forces are almost equivalent. The United Kingdom shows the highest innovative verve $\left(b_{1}\right)$ and also the highest adaptive push $\left(b_{3}\right)$, i.e. the strongest dynamic competition. Germany shows a strong innovative verve and a low adaptive push while France presents an innovative verve a little lower than Germany, but a much higher adaptive push. Relative to Germany, France has a lower parameter on the term in equation (1) decelerating innovative verve; and a higher parameter on the term in equation (2) decelerating adaptive push. These offsetting values of $b_{1}$ and $b_{3}$, and $b_{2}$ and $b_{4}$ tend to partly compensate for the differences in innovative verve and adaptive push, making the disequilibrating-equilibrating process closer in those two countries. The United Kingdom shows such offsetting behavior only with reference to the adaptive push (but the difference between $b_{3}$ and $b_{4}$ is large), while the parameter $b_{2}$, decelerating the innovative verve, appears higher than France and lower than Germany, implying for this aspect a widening of the disequilibrating forces relative to Germany.

\section{Conclusion}

This paper has insisted on the possibility and importance of measuring radical uncertainty and has shown the usefulness of survey results in this regard. In particular, the study has shown that such a measure can improve both the results and use of the business surveys and the understanding of the relation between innovation and uncertainty.

The empirical applications give a proof of both the solidity of our development of indicators as derived by Business Tendency Surveys and the profitableness of their use in modelling and ad hoc analyses. Moreover, the research points out the close relation between innovation and uncertainty that, as is well known, crucially influences growth and development and allows an aggregate representation of the processes of dynamic competition and its cyclical behaviour.

Utilizations of other aspects of the Business Tendency Surveys could be added, such as the quantification of additional indicators and some additional correction of the current percentage of the modalities of survey answers. Regional disaggregations and some refinement of the data could be provided. The second (direct) indicator of uncertainty requires further running-in and some longer data series. However, our results seem to show the usefulness of the proposed empirical investigations.

\section{Acknowledgements}

We thank: M. Malgarini of ISTAT for his suggestions, particularly the additional question of the ISAE quarterly business surveys, a question providing our second indicator of uncertainty; Murray Pellissier, Bureau of Economic Research (BER), University of Stellenbosch, South Africa, who provided the results of the enquiries on business conditions for South Africa and engaged in useful discussions with the author; Angelo Reati, former official of the European Commission, provided intensive and helpful discussion; Clifford R. Wymer, authored the software used for computation and estimation (WYSEA package Wymer System for Simulation and Estimation Analyses).

\section{References}

Arrow, K. J. (1953). The role of securities in the optimal allocation of risk bearing. Review of International Studies, 31.

Arrow, K. J. (1984). The economics of information. Collected papers of Kenneth J. Arrow, Blackwell, Oxford.

Calcagnini, G., \& Saltari, E. (1997). Un'analisi del principio dell'acceleratore in condizioni di incertezza. Rassegna dei Lavori dell'ISCO.

Cantner, U., Hanusch, H., \& Pyka, A. (1998). Routinized innovations: Dynamic capabilities in a simulation study. In Eliasson, et al. (Eds.), The microfoundations of economic growth. University of Michigan Press.

Davidson, P. (1988). A technical definition of uncertainty and the long run non neutrality of money. Cambridge Journal of Economics, 12(3).

Davidson, P. (1994). Post Keynesian macroeconomic theory. Aldershot: Edward Elgar.

Davidson, P. (1995). Uncertainty in economics. In S. Dow \& J. Hillard (Eds.), Keynes, knowledge and uncertainty. Aldershot: Edward Elgar.

De Finetti, B. (1964). Foresight: its logical laws, its subjective sources. In H. E. Kyburg \& H. E. Smokler (Eds.), Studies in subjective probability. New York: John Wiley. 
Dow, S. (1995). Uncertainty about uncertainty. In Dow, S., \& Hillard, J. (1995) (Eds.), Keynes, knowledge and uncertainty. Aldershot: Edward Elgar.

Drucker, P. F. (1985). Innovation and entrepreneurship. Heinemann, London.

Ekstedt, H., \& Fusari, A. (2010). Economic theory and social change, Problems and revisions. London, New York: Routledge.

Fusari A., \& Reati, A. (2013). Endogenizing technical change: a long term view of sectoral dynamics. Structural Change and Economic Dynamics (SCED), 24, 76-100. http://dx.doi.org/10.1016/j.strueco.2012.06.004

Fusari, A. (1996). Paths of economic development: modelling factors of endogenous growth. International Journal of Social Economics, 23(10/11), 164-191. http://dx.doi.org/10.1108/03068299610149525

Fusari, A. (2004). Uncertainty, competence and the theory of the firm. Some crucial omission and misunderstanding of the current debate. Shifting Boundaries Conference, 2-3 September. Bristol Business School and 2005 Second Meeting Of ENEF, Erasmus University, Rotterdam, 8-9 September.

Fusari, A. (2005). A model of the innovation-adaptation mechanism driving economic dynamics: A micro representation. Journal of Evolutionary Economics, 15(3), 297-333. http://dx.doi.org/10.1007/s00191-005-0246-z

Fusari, A. (2006). Radical uncertainty indicators: Quantitative specifications and applications. $28^{\text {th }}$ CIRET Conference, Rome.

Fusari, A., \& Pellissier, M. (2008). Some new indicators and procedure to get additional information from the Business Tendency Surveys. $29^{\text {th }}$ CIRET Conference, Santiago de Chile.

Galavotti M. C., Scazzieri, R., \& Suppes, P. (2008). Reasoning, rationality and probability. Center for the Study of Language and Information.

Griliches, Z. (1990). Patent statistics as economic indicators: a survey. Journal of Economic Literature, XXVIII, 1661-1707.

Harsanyi, J. C. (1967). Games with incomplete information played by Bayesian palyers I-III Part. I. The basic model. Management Science, 14(5).

Hayek, F. A. (1937). Economics and knowledge. Economica, 4.

Hirshleifer, J. (1989). Time, uncertainty, and information. Oxford, B. Blackwell.

Hirshleifer, J., \& Rilay, J. G. (1992). The analytics of uncertainty and information. Cambridge: Cambridge University Press. http://dx.doi.org/10.1017/CBO9781139167635

Hodgson, G. M. (1999). Evolution and Institutions. Edward Elgar Cheltenham, UK, Northampton, MA, USA.

Kahneman, D., \& Tversky, A. (1979). Prospect theory: an analysis of decision under risk. Econometrica, 51. http://dx.doi.org/10.2307/1914185

Keynes, J. M. (1937). The general theory of employment. Quarterly Journal of Economics, 51. http://dx.doi.org/10.2307/1882087

Kirzner, M. I. (1973). Competition and Entrepreneurship. Chicago and London: The University of Chicago Press.

Kirzner, M. I. (1985). Discovery and the Capitalist Process. Chicago and London: The University of Chicago Press.

Knight, F. H. (1950). Risk, uncertainty and profit. La Nuova Italia, Firenze.

Lawson, T. (1985). Uncertainty and economic analysis. Economic Journal, 15. http://dx.doi.org/10.2307/2233256

Lupton, D. (2003). Risk and everyday life. Thousand Oaks, CA: Sage Publications.

Machina, M. J. (1982). Expected utility Analysis without the independence axiom. Econometrica 50(2). http://dx.doi.org/10.2307/1912631

Morroni, M. (2006). Knowledge, Scale and Transactions in the Theory of the Firm. Cambridge University Press. http://dx.doi.org/10.1017/CBO9780511617232

Mueller, D. C., et al. (1990). The dynamics of company profits. Cambridge University Press. http://dx.doi.org/10.1017/CBO9780511664724 
Nelson, R. R., \& Winter, S. G. (1982). An Evolutionary Theory of Economic Change. Cambridge Mass., London: The Belknap Press of Harvard University Press.

Odagiri H. (1994). Growth through competition, competition through growth. Oxford: Clarendon Press. http://dx.doi.org/10.1093/0198288735.001.0001

Pellissier, G. M. (2006). Evaluating the impact of disaggregated survey panel response on Business tendency survey results. OECD Workshop, Rome.

Pellissier, G. M. (2007). Business conditions Response: Volatility versus Non-volatility. Mimeo, Bureau of Economic Research, Stellenbosch.

Peschel, M., \& Mende, W. (1986). The predator- prey model. Wien, New York: Springer-Verlag.

Pindyck, R. S. (1991). Irreversibility, Uncertainty, and investment. Journal of Economic Literature, XXIX, 1.

Polanyi, M. (1966). The tacit dimension. Garden City, NY, Doubleday.

Runde, J. (1998). Clarifying Frank Knight's discussion of the meaning of risk and uncertainty. Cambridge Journal of Economics, 22(5), 539-546.

Savage, L. (1954). The foundation of statistics. New York: John Wiley.

Saviotti, P. P., \& Pyka, A. (2004). Economic development by the creation of new sectors. Journal of Evolutionary Economics, 14. http://dx.doi.org/10.1007/s00191-003-0179-3

Scazzieri R., \& Marzetti, S. (2011). Fundamental uncertainty: rationality and plausible reasoning. New York, Basingstoke: Palgrave MacMillan.

Schumpeter, J. A. (1934). The theory of economic development. Cambridge Mass: Harvard University Press.

Shackle, G. L. S. (1990). Time, expectations and uncertainty in economics Selected essays. J. L. Ford editor Aldershot, Edward Elgar.

Simon, H. A. (1997). Models of bounded rationality. Empirically grounded economic reason, 3. Cambridge, Mass: The MIT Press.

Ulph, A., \& Ulph, D. (1994). The irreversibility effect revisited. Department of Economics, University of Southampton.

Vercelli, A. (1999). The recent advances in decision theory under uncertainty: A non-technical introduction. In L. Luini (Ed.), Uncertain decisions. Bridging theory and experiments. Boston: Kluwer Academic Publishers. http://dx.doi.org/10.1007/978-1-4615-5083-9_11

White, A. R. (1972). The propensity theory of probability. British Journal for the Philosophy of Science, 23(1). http://dx.doi.org/10.1093/bjps/23.1.35

Wymer, C. R. (1993). Resimul and Escona programs, manual and documentation (mimeo). WYSEA Systems Estimation and Analysis (computer package).

\section{Notes}

Note 1. Econometric estimation uses some of C. R. Wymer's programs, which form part of the WYSEA (System Estimation and Analysis) package.

Note 2. An example of the common confusion between expectation and uncertainty can be found in Calcagnini and Saltari (1997), who use ISCO surveys but do not derive uncertainty from the volatility of expectations but rather from aggregate data on the percentage of firms expecting stability, increase or decrease of certain variables.

Note 3. See A. Fusari, Innovation, uncertainty, entrepreneurship: modelling the dynamic process of the economy, chapter 5 of H. Ekstedt and A. Fusari, (2010), Routledge, London and New York.

Note 4. A more appropriate volatility indicator can be expressed by giving a double weight to the double jumping in the changes of answer, i.e. to $R_{13}$ and $R_{31}$, that is, as follows:

$\mathrm{OV}=\mathrm{R}_{12}+2 \mathrm{R}_{13}+\mathrm{R}_{21}+\mathrm{R}_{23}+2 \mathrm{R}_{31}+\mathrm{R}_{32}$

Note 5. ISAE was charged with the execution, for Italy, of the Business Tendency Surveys harmonized at European level. But after 2010, ISAE was closed and the charge was transferred to ISTAT (Italian National Institute of Statistics).

Note 6. Another indicator of uncertainty may consist in the specification, by way of surveys, of a min-max range 
of expectations, where the distance between the minimum and maximum expectation may be considered an expression of the degree of uncertainty. In addition, the standard deviation of foresights may be interpreted as a measure of uncertainty.

Note 7. Other indicators may be derived, for instance: positive and negative disposition, that is, the variation over time of the total frequency of expected (and ex post) increases or decreases (Up or Down); or again: the ratio between the frequency of changes in a modality of answer and the total frequency of that modality, thus giving an indication of the 'turbulence' of the considered modality.

Note 8. Some estimates for South Africa have been performed using data provided by M. Pellissier, of the Stellenbosch University and BER (South Africa) surveys and publication, in the context of an extended collaboration on volatility of BTS answers.

Note 9. Some others computations and graphs on relevant indicators are set out in Fusari A. \& Pellissier M. (2008).

Note 10. If the weight of the repeated answer $\left(\mathrm{R}_{11}\right)$ is supposed, for instance, to be 3 , the expression above becomes: $\left(\mathrm{Up}+2 \mathrm{R}_{11}\right) / 4$.

If we take the numerator of the second expression for the permanence indicator (in section 3) giving a weight of 2 to it, we get the following expression for correction of $\mathrm{Up}:\left(\mathrm{R}_{11}+4 \mathrm{R}{ }_{11}+\mathrm{Up}\right) / 7$. For the correction of Same and Down we have to substitute in the expression, respectively, Same or Down to Up and $R_{22}$ or $R_{33}$ to $R_{11}$.

Note 11. In fact, [ModifiedUp/modified(Up+Same+Down) + ModifiedSame/modified(Up+Same+Down) + Modified Down/modified(Up+Same+Down) $]^{*} 100=100$

Note 12. An extensive analysis of this interaction, along with some simulation experiments, may be found in A. Fusari (2005) and Ekstedt \& Fusari (2010).

Note 13. See I. M. Kirzner (1973 and 1985).

Note 14. See J. A. Schumpeter (1934).

Note 15. This matter, indeed, goes well beyond economics. Research on social and historical processes, from primitive ages to the beginning of modern dynamic society, shows the important role played in historical evolution by binomial innovation-adaptation. See A. Fusari, Human adventure; an inquiry on the way of people and civilizations, Italian edition. SEAM, Roma 2000.

Note 16. Alternatively, a three-equation predator-predator-prey model could be specified, with innovation that preys upon (uses) entrepreneurial skill and is preyed upon by uncertainty, that also preys upon (i.e. stimulates the use of) entrepreneurial skill.

Note 17. See D. C. Mueller et al. (1990); H. Odagiri (1994).

Note 18. The fact that only two observations were outliers, that the model is dynamic, and that there is no reason to assume that the causes, if any, of these anomalies were the same, suggested that the use of a dummy variable was inappropriate. 